\title{
Do Jornalismo e da História à História do Jornalismo'
}

\author{
Felipe Pontes
}

Resumo

O texto aponta algumas aproximações entre História e Jornalismo, estudando o percurso teórico de cada uma dessas áreas e as conexões possíveis a partir da constituição do conceito de História do Jornalismo. Tem por base os resumos das teses e dissertações de pós-graduação em Comunicação do Brasil que discutem o tema, estabelecendo primeiramente quais tratam o Jornalismo e, dentre estes, os que pesquisam a História do Jornalismo. O estudo trata da formação de um campo de saber jornalístico a partir da busca por sua autonomia conjugada ao desenvolvimento conceitual e teórico da História para uma compreensão das dificuldades e potencialidades pertinentes à História do Jornalismo. Por fim, estabelece que tanto a abertura da História para os outros campos de saber quanto a falta de um objeto justificado e delimitado por parte do Jornalismo permitem a entrada de outras áreas para a composição das pesquisas em História do Jornalismo, tais como a Sociologia, a Economia, a Política e os Estudos da Linguagem.

Palauras-chave:

Jornalismo, História, História do Jornalismo, Estratégias teórico-metodológicas, Pós-graduação

\section{From Journalism and from History to History of Journalism}

Sobre $\bullet$ autor Mestrando em Jornalismo na Universidade Federal de Santa Catarina (UFSC). felipe271184@yahoo.com.br

\section{Abstract}

This text presents some approaches between History and Journalism, studying the theoretical route of each one of these areas and the possible links from the constitution of History of Journalism concept. It has as foundation the abstracts of the thesis and papers from post-graduate in Communication of Brazil which discusse this subject, establishing, first of all, which treat Journalism and, among these, which research History of Journalism. The study treats the formation of a jornalistical knowledge field from the search for its autonomy conjugated the development conceptual and theoretical of History for an understanding of the difficulties and the possibilities belonging to History of Journalism. Finally, it establishes that as much the opening from History to the others knowledge fields as the lack of a justified and limited object from Journalism permit the entry by the others areas for the composition of the researches in History of Journalism, such as Sociology, Economy, Politics and Language Studies.

Key words:

Journalism, History, History of Journalism, Theoretical and methodologycal strategies, Post-graduate 


\section{Historiador, Comunicólogo, Jornalista ou o que?}

O problema mais comum decorrente de um trabalho de História do Jornalismo é uma certa crise de identidade do pesquisador. Isso não é resultado de qualquer problema de personalidade nem é constatado a partir de entrevistas com os autores dessa área. É percebido no produto final, na composição das pesquisas, nas tentativas de alicerces teórico-metodológicos que os autores querem sustentar. Por vezes, a estratégia é afirmar-se historiador, colocando nessa acepção uma analogia à cientificidade - o que o campo da História luta para ser e não ser ao mesmo tempo. Por outras, diz-se comunicólogo, ou pesquisador das comunicações, o que revela um pesquisador híbrido na utilização de métodos e teorias, resultado dos debates para a consolidação do campo da Comunicação [como exemplifica o trabalho de José Luiz Braga (2001)]. Colocar-se como pesquisador em jornalismo é ainda mais difícil, visto que a analogia mais comum a essa identidade remete o pesquisador à sua prática profissional. Mesmo assim, alguns se dizem jornalistas e buscam justificar suas conclusões a partir do que essa subárea já produziu de conhecimento. Por fim, muitos que pesquisam a História do Jornalismo alicerçam-se numa postura de interdisciplinaridade, por vezes misturando Economia e Política para se dizer materialista-dialético; Literatura e Cultura para posicionar-se ao lado das narrativas; tomando os Estudos da Linguagem (dentro de sua imensa variabilidade de formas) para estudar as intenções, os sentidos e as estruturas; ou a Sociologia para catalogar uma profissão e as categorias de produção de um conhecimento.

Mas, não é o pesquisador o foco desse texto (ainda que ele seja um ator principal da cena que será composta). A pertinência dessa crise de identidade é a posição do Jornalismo como campo de estudo em relação às Ciências Sociais e Humanas em geral. Dois conceitos tentam responder a esse problema: a que aponta o Jornalismo numa posição de fronteira teórica; e a que o coloca como dependente de lentes para ser estudado. Pressupor que o Jornalismo localiza-se em uma região de fronteira sugere, conseqüentemente, que ele possui uma região (mesmo que essa região seja tênue). Já, se o Jornalismo pode ser tratado a partir das lentes, como traçado por Barbie Zelizer (2004), ele estaria localizado apenas no objeto (a partir do que é visto) ou estaria fadado a um "problema de visão" (a partir de quem vê). A região de fronteira permite a discussão de um conhecimento do Jornalismo, visto que dá pistas para a constituição de uma região de retorno no exercício da pesquisa nesse segmento. Por sua vez, a analogia às lentes pressupõe a necessidade do auxílio de uma outra ciência e traz implícita uma provocação que será levada ao longo do texto: o jornalismo como prática social pode ser visto pela pesquisa em jornalismo a olho nu?

${ }^{1}$ Esse texto, com pequenas alterações, foi apresentado no VI Encontro Nacional de História da Mídia, no GT História do Jornalismo. 
Quando se fala de História do Jornalismo, essa posição fronteiriça fica mais tênue e a possibilidade do reconhecimento do Jornalismo independente de outras áreas, mais difícil. Como soma, é possível verificar que o próprio estatuto da História também é construído sobre hibridações. Ainda que a História tenha o respaldo do tempo para demarcar sua (uni) presença, para além dessa metafísica ela não possui uma unicidade teórica ou metodológica. Pode-se dizer que tudo tem uma história. Contudo, se for retirado esse "tudo", a História se desfaz. A História, por isso, possui sua possibilidade de existência em um "de" que lhe acompanha e polariza suas relações. Assim, pode-se falar em História da Política, História da Economia, História das Artes, História das Ciências, História do Jornalismo. A História do Jornalismo, portanto, abre margens duplicadas para a entrada de outros campos, de outras lentes que redirecionam o olhar para e o olhar de dessas pesquisas. Isso incide sobre a escolha dos objetos, os conceitos e teorias formuladas e no tipo de metodologia empregada para as diferentes pesquisas com esse tema. As crises tornam-se inevitáveis.

O texto que segue discute a formação do Jornalismo como um campo de saber, trazendo para a pauta dos estudos na área a interface com as outras ciências, a sua relação com a Comunicação e as teorias que dão contornos a essa "região de fronteira". Juntamente, discute nuances das transformações da disciplina História, especialmente o debate francês, buscando articular o conceito holístico de História com a dispersão desse conceito em histórias com interesses voltados para as séries da qual estão inseridas. Para, a partir disso, tratar da História do Jornalismo como possibilidade de observar a História em favor de um reconhecimento do Jornalismo como área de saber.

\section{A formação de um campo de saber do Jornalismo}

O conceito de campo que é utilizado nesse texto advém, estruturalmente, da definição de Pierre Bourdieu (1983: 122) de campo científico, entendendo-o como o lugar, o espaço de jogo de uma disputa pela autoridade científica, definida como uma capacidade técnica e poder social; ou pela competência científica, compreendida enquanto capacidade de falar e de agir legitimamente. Adriano Duarte Rodrigues (1990: 144), sistematizando essa definição, concebe campo como a "esfera de legitimidade que impõe com autoridade indiscutível atos de linguagem, discursos e práticas uniformes dentro de um domínio específico de competência”. Esse conceito não se alicerça apenas pelo objeto de observação (o Jornalismo em sua prática social), mas também como espaço de formulação teórica sobre esse objeto. Ou seja, a possibilidade de um campo jornalístico para esse estudo excede a definição de Bourdieu (1997) e de Traquina (2004), visto que estes o definem apenas a partir da produção de notícias.
A História do Jornalismo abre margens duplicadas para a entrada de outros campos, de outras lentes que redirecionam o olhar para e olhar de dessas pesquisas 
Ainda que o Jornalismo não constitua um campo de saber legitimado cientificamente diante de outras áreas e não formalize sua posição como conhecimento epistemológico, a história de seus estudos também não está fadada a um modo genérico de encarar a sociedade. O Jornalismo possui uma atividade de pesquisa e, decorrente de um processo de institucionalização, busca alicerçar essa prática. Essa busca perpassa pela competência de arregimentar conceitos capazes de explicar um dado objeto exclusivo de uma maneira igualmente particular e pela capacidade de articulação de obras, grupos de estudos, faculdades, sociedades científicas etc. Portanto, uma autonomia epistemológica, capaz de determinar a particularidade da pesquisa em Jornalismo, e uma autonomia política, que visa demarcar posições e garantir espaço na disputa com os outros campos de saber.

O entendimento dessa disputa política entranhada na responsabilidade epistemológica aponta para a posição paradoxal em que se encontra a pesquisa em Jornalismo em relação a outros campos de saber. O jornalismo, especialmente nos últimos 150 anos, possui um alto número de estudos envolvendo diferentes processos metodológicos, teóricos e de disputas com outros saberes. Prova disso é que os institutos de pesquisa em Jornalismo na Alemanha coordenados por Karl Bücher datam da década de 1880, período em que a Sociologia também lança seus alicerces a partir dos cursos de Émile Durkheim na França e de Max Weber na Alemanha.

Nota-se, ainda nesse período, como os campos atuais das Ciências Humanas (como a Sociologia, a Antropologia, a Psicologia e a Lingüística) estavam imbricados em análises filosóficas, políticas e econômicas. O jornalismo não estava em uma posição diferente. Karl Marx, por exemplo, no desenvolvimento de seu compêndio econômico e político, lançou as bases para a Sociologia, mas também contribuiu para o Jornalismo ao estudar a importância da liberdade de imprensa. Karl Bücher (1901), economista, parte do estudo do Jornalismo como uma das engrenagens da máquina comercial do fim do século XIX, tentando entender a formação de uma opinião pública. Robert Park (1904) começa seus estudos em Jornalismo para, a partir deles, fundar a Sociologia estadunidense. Gabriel Tarde (1901) busca compreender a psicologia das multidões com a intenção de entender a influência que também os jornais podem exercer sobre o público e sobre a política. Como aponta Hanno Hardt (2001) e demonstra o trabalho de Berger e Marocco (2007), o final do século XIX e início do século XX possuem muitos exemplos de estudos que fundam e alimentam outros campos de conhecimento concomitantemente ao campo jornalístico.

O Jornalismo também manteve um percurso acadêmico ao longo do século XX, com produções que visavam entender o fenômeno jornalístico. Exemplo dessa continuidade e especificidade de
Os institutos

de pesquisa

em Jornalismo

na Alemanha

coordenados por

Karl Bücher datam

da década de 1880,

período em que a

Sociologia também

lança seus alicerces 
pesquisa está nas obras de Otto Groth, que permanecem pouco conhecidas e citadas pelos autores brasileiros diante da dificuldade da obra estar toda em alemão. Nos Estados Unidos, os estudos em Jornalismo também se desenvolveram, com a abertura de cursos de graduação na área promovida por Willard Bleyer em 1903 e do curso de doutorado em Jornalismo fundado em meados da década de 20 pelo mesmo pesquisador.

No Brasil, como aponta Meditsch (1992), os cursos de Jornalismo, em sua maioria, foram rapidamente transformados em Comunicação Social diante da política do Centro Internacional de Estudios Superiores de Periodismo para a América Latina (Ciespal). Essa tendência de transformar os estudos de Jornalismo em Comunicação teve origem nos Estados Unidos ${ }^{2}$, como explica Rogers (1997: 445-495), a partir da fundamentação da disciplina da Comunicação por Wilbur Schramm e pelo contexto político-estratégico que esses estudos ocuparam durante a II Guerra Mundial e a Guerra Fria. O Jornalismo passou a integrar-se ao conceito de meios de comunicação de massa ou midia e a participar do fenômeno da Comunicação Social como um todo, ao lado da Publicidade, da Propaganda, do Cinema e do entretenimento em geral. O jornalismo é tratado como meio, como suporte, como portador de uma mensagem e possibilitador da comunicação. Essa definição não é errada. Contudo, parece não contemplar a especificidade que o Jornalismo busca nesses últimos 150 anos.

Para uma visão da disputa conceitual empreendida pelo Jornalismo diante da Comunicação e das demais áreas das Ciências Humanas e Sociais, é preciso, por vezes, inverter a relação do Jornalismo com os outros campos para que seja possível achar alguns contornos do que poderia ser essa "estreita região de fronteiras". As outras áreas, ao usarem o Jornalismo para alimentar suas teorias, acabam contribuindo também para demandas do próprio campo. Por outro lado, muitos pesquisadores do Jornalismo vão até essas áreas para buscar elementos que respondam a suas pesquisas. Assim, a Economia possui um importante papel para o Jornalismo quanto à circulação e difusão das informações. As Ciências da Informação auxiliam o pesquisador em Jornalismo no estudo dos suportes tecnológicos, nas potencialidades pertinentes aos dispositivos informativos. A Lingüística contribui para os estudos dos discursos e das estruturas das notícias. A Antropologia pode contribuir permitindo a compreensão do simbolismo inerente tanto ao hard news quanto às notícias de interesse humano. É possível demonstrar, nesses casos, que o Jornalismo, ao entrar em outros campos, pode demarcar sua especificidade e um certo "lugar de retorno".

Já quando colocado em relação com a Comunicação, a posição do Jornalismo parece mais "entranhada". Isso porque o Jornalismo em sua prática social e profissional tem a comunicação

${ }^{2}$ Nota-se, contudo, que nos Estados Unidos essa transformação de Jornalismo para Comunicação não aconteceu em vários cursos. 
como princípio básico, já que se trata de um processo de conversação social $^{3}$ (um jornalista conta para o público o que ocorreu em um dado lugar e tempo) e produz conversação social (as notícias são comentadas e difundidas pelo público). Contudo, o Jornalismo não é qualquer conversação social. Ele difere da Publicidade, da linguagem do Cinema ou ainda de uma revista em quadrinhos. O Jornalismo possui um vínculo com os fatos ${ }^{4}$ que acontecem na realidade social e possuem algum sentido no presente. Enquanto a Comunicação está interessada em qualquer processo de conversa que acontece na sociedade (seja ela persuasiva, estética ou inventiva) entendendo os sentidos decorrentes dela, o Jornalismo possui a especificidade de tratar algo que aconteceu e que precisa ser compreendido pelo público como algo que aconteceu. Nota-se nessa relação que o Jornalismo não está apenas na produção da notícia, mas também no processo de entendimento e de resposta do público. A persuasão, a estética e a ficção estão no Jornalismo - e sem dúvida o compõem - mas não são os únicos elementos e nem os mais importantes. Diferentes de outros setores da comunicação como a Publicidade (verticalmente persuasiva) e o Cinema (caracteristicamente fundado na estética), por exemplo.

Portanto, o Jornalismo é aqui questionado como uma possível região epistemológica de análise do fenômeno jornalístico em sua completude, referendando a interferência dessa prática nos diferentes sistemas culturais e políticos de uma dada sociedade. Isso revela uma unicidade prática e teórica do conceito de Jornalismo, visto que tanto a visão advinda da academia quanto da prática dos jornalistas respondem ao mesmo fenômeno Jornalismo. Essa posição amplia a abrangência do Jornalismo, por vezes pensado apenas como um processo de produção de um dado bem simbólico (da notícia, por exemplo), para uma relação institucionalizada que estabelece formas de conhecimento para alicerçar suas práticas e compreender seu funcionamento.

O que se presume a partir disso é que uma teoria do Jornalismo deve responder também a questões que excedam às atividades das redações, à produção da notícia ou aos critérios de noticiabilidade. Uma teoria do Jornalismo não pode ser apenas aplicada à prática profissional do jornalista. Ela deve ser capaz de perceber também a constituição da prática jornalística no seio da sociedade, a dinâmica de suas relações com outros campos como a Política, a Economia e o Direito, a produção de uma linguagem particular ao campo, sua predisposição a ser o vértice da produção de imaginários sociais e a necessidade social da notícia, ou seja, a necessidade do público em querer se informar. O objeto de uma teoria do Jornalismo, portanto, é a centralidade do Jornalismo como prática social e cultural.

${ }^{3}$ Braga (2001: 15-17) aponta que o objeto da Comunicação seria o que há de conversacional e de troca nas instâncias e situações da vida social.

${ }^{4}$ Considero o fato aqui como qualquer fenômeno que acontece no mundo ontologicamente, independente de qualquer valor subjetivo. 
Contudo, essa definição ampla do que é o objeto de uma teoria do Jornalismo permite que outras esferas de saber reivindiquem o papel de investigar o Jornalismo. Como demonstra Zelizer (2004), áreas como a Sociologia, a História, a Cultura, a Política e os Estudos da Linguagem são usadas por pesquisadores do Jornalismo como lentes para observar esse objeto. A maioria dos trabalhos de pesquisa em jornalismo fundamenta seus conceitos em teorias de outras áreas de saber e utiliza as ferramentas metodológicas que originalmente foram constituídas para fornecer respostas pertinentes a essas áreas. Diante de tantas pesquisas dessa natureza, muitas vezes o Jornalismo parece precisar de outras áreas para se definir, o que o determina apenas como objeto, mas retira seu status de teoria.

A resposta de muitos pesquisadores para essa situação híbrida das teorias sobre o Jornalismo é metonímica. Eles enfatizam que o objeto do jornalismo é o processo de produção da notícia, os critérios de noticiabilidade ou está centralizado no trabalho do jornalista [exemplo disso são os trabalhos de Gomis (1991), Souza (2002) e Traquina (2004)]. Por isso consideram sinônimas a Teoria do Jornalismo e a Teoria da Notícia. Ou seja, tomam parte do objeto do Jornalismo como todo o objeto para a determinação da Teoria do Jornalismo.

Para o estabelecimento do objeto do Jornalismo não basta tomar parte de sua especificidade. Por outro lado, o desafio é tencionar as pesquisas que fundamentam seus conceitos, métodos e objetivos a partir de outras áreas. Tomando como pressuposto que o Jornalismo para essas pesquisas é visto a partir de lentes, é preciso questionar o lugar de onde parte esse olhar e buscar retirar-lhe as lentes e verificar se o objeto continua visível. Portanto, não reduzir o objeto, problematizá-lo diante de sua fragilidade e explorá-lo em suas frestas. Tornar essa abertura teórica do Jornalismo uma possibilidade para a compreensão da potencialidade desse objeto e do desafio para estabelecer conceitos que auxiliem no seu entendimento.

\section{A História e suas histórias}

A emersão das Ciências Humanas a partir do século XIX mudou a configuração e o entendimento da História como uma área de conhecimento. A História, como aponta Foucault (2002: 508517), pode ser considerada a primeira ciência do homem, uma espécie de "mãe das Ciências Humanas". A História, desde os gregos, passando pelos estóicos e pela Idade Média, estava relacionada a um movimento único, ou ligada a uma espécie de cronologia cósmica ou a um devir do mundo, uma espécie de destino humano. Nota-se que essa visão filosófica estava fortemente arraigada ao conceito de História em Hegel e demonstra uma

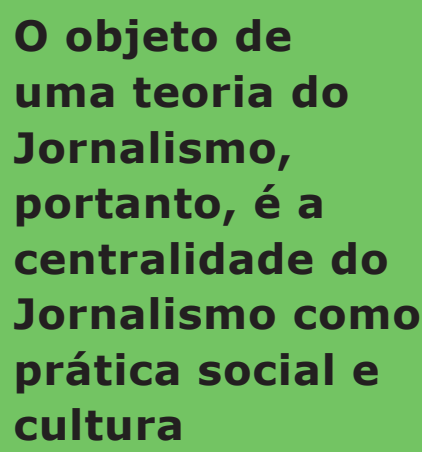

O objeto de uma teoria do Jornalismo, portanto, é a centralidade do Jornalismo como cultura 
proximidade estrutural com o modo de pensar a história da humanidade em Comte ou Marx. A visão de totalidade e unicidade histórica é alterada com o surgimento das ciências da vida, do trabalho e da linguagem (Foucault, 2002). Marx mesmo demonstra um processo de transição na História, já que vai estudar a evolução das diferentes formas de trabalho a partir de categorias que emergem da ciência do trabalho, no caso, a Economia. Os filólogos passam a verificar a evolução da linguagem não apenas pela política, migrações ou guerra, mas na própria dinâmica interna da fonética e da gramática. E a vida passa a ser compreendida por processos de evolução, seleção natural e mutação.

Essa tendência de variabilidade da História ganha mais impulso diante do surgimento de disciplinas como a Psicologia, a Sociologia, a Etnologia (Antropologia) e a Lingüística. Pode-se afirmar que todas essas disciplinas, na busca pelo alicerce de suas posições, desafiaram a História, buscando retirá-la do posto de discurso universal e unificador das Ciências Humanas. No início do século XX, a Sociologia irá criticar a visão política e nacionalista da História e reivindicar a cientificidade de sua área para os estudos do passado. Levi-Strauss (1976: 336), por sua vez, aponta a História globalizante e transcendental como um tipo de mito. Para ele, a História só pode ser parcial, visto que não há totalidade histórica (como aponta Marx e Hegel), mas várias histórias que não estão ligadas a um tema central. Essa via de análise permitiria, como aponta Dosse (2001: 152-158), uma história dos pequenos acontecimentos, ou de histórias descontínuas, tendo a Antropologia como ciência capaz de analisar todas essas condições, visto que ela poderia decifrar as estruturas imanentes na sociedade, diferentemente da História, que ficaria restrita aos fatos diretamente observáveis. Antes ainda, Saussure (2001: 23-25) vai tentar fundamentar uma disciplina dos signos que explique os fatos sociais da vida humana como um todo, no caso, a Semiologia. Essa disciplina abarcaria todos os fenômenos relacionais do homem, incluindo sua história. A partir desses dois autores, grande parte do Estruturalismo trouxe consigo essa visão de uma História cindida e descontínua.

Outra crítica contundente à História como única foi colocada por Foucault e sua Arqueologia do Saber. Para o autor, o objeto da pesquisa histórica deve ser tratado como particularizado a partir de uma série da qual ele faz parte, com as regras inerentes a essa série. Ele, considerando um elemento definido em uma série, procura reconhecer a regularidade dos fenômenos e os limites da probabilidade de sua emergência. Assim, a análise requer que se estabeleçam "as séries diversas, entrecruzadas, divergentes, muitas vezes, mas não autônomas que permitem circunscrever o 'lugar' do acontecimento, as margens de sua contin-
A visão de totalidade e unicidade histórica é alterada com o surgimento das ciências da vida, do trabalho e da linguagem 
gência, as condições de sua aparição" (Foucault, 2005b: 56). Essa história serial opõe-se aos grandes esquemas totalizantes. Outra proposta de Foucault é a descontinuidade dos acontecimentos, justamente para verificar as rupturas e valorizá-las, em oposição a uma tentativa de buscar a uniformidade explicando as diferenças a partir de um mesmo sistema, de um continuum.

Todas essas críticas à disciplina histórica provocaram mudanças e o surgimento de novas áreas de interesse. Ainda que seja considerada a força da herança hegeliana, das pesquisas histórico-dialéticas de cunho marxista e do Histocismo de Dilthey (tradições marcadamente da História Alemã), a disciplina História, em especial na França, sofreu modificações, gerando novas tendências que influenciam ainda hoje a historiografia brasileira e, particularmente, os estudos em História do Jornalismo.

A primeira grande mudança no modo de trabalhar dos historiadores foi realizada por Marc Bloch e Lucien Febvre com a criação da revista Annales d' histoire économique e sociale e, posteriormente, da Escola dos Annales a partir de 1929. Segundo François Dosse (2001: 20-21), a Escola dos Annales foi criada para fazer frente à tradição historiográfica francesa de então que valorizava uma História política e factual voltada para exaltar os governantes e as grandes batalhas da nação francesa. Tomando como parte a crítica empreendida pela Sociologia, os autores da chamada primeira fase dos Annales buscam incluir métodos da Economia, da Sociologia e da Geografia para uma fundamentação estatística, demográfica e produtiva da história. É característica dessas análises, ainda, o lançamento de uma espécie de "psico-história" que ficou conhecida como a história das mentalidades, uma área voltada para o desenvolvimento do saber e das correntes de pensamento na humanidade e que vai sofrer mutações nos 50 anos seguintes, especialmente por causa da história das ciências inaugurada por Gaston Bachelard e seguida por George Canguilhen e das grandes transformações decorrentes do movimento arqueológico do saber de Foucault.

Após a II Guerra Mundial, Fernand Braudel caracteriza o que é conhecida como a segunda fase dos Annales. Como aponta Dosse (2001: 151-172), a crítica estruturalista realizada por Lévi-Strauss encontrou uma resposta da História a partir das modificações teóricas feitas por Braudel. Primeiramente, Braudel fez a defesa por uma história total, entendendo que todas as relações são históricas e cabe à História observar, classificar, comparar e isolar todos os fatos pertencentes às outras ciências humanas, inclusive às estruturas imanentes da Etnologia. A História de Braudel é estruturada em uma relação temporal. Para ele existiriam três temporalidades, três domínios em que a História explicaria a realidade: uma história quase imóvel
A disciplina História, em especial na França, sofreu modificações, gerando tendências que influenciam os estudos em História do Jornalismo 
que trata a relação do homem com o seu meio geográfico; uma história lenta, que trata dos ciclos econômicos e das estruturas sociais; e uma história de acontecimentos, capaz de relatar a experiência do indivíduo e as oscilações breves da vida cotidiana e presente. Como unificadora dessas temporalidades na História e fundadora da evolução dos homens e das coisas estaria a longa duração, ou seja, um discurso histórico que interliga natureza e cultura, permeando todas as relações possíveis. Isso significa que, contrário à posição de Lévi-Strauss que coloca a Etnologia como a responsável por descrever as estruturas imanentes de sociedade, Braudel praticamente congela a História, dando a ela a capacidade de descrever as estruturas mais permanentes em qualquer sociedade, superando, inclusive, a lentidão da temporalidade geológica. Dosse (2001, p. 165-170) conclui que, nesse tipo de análise, o homem está cada vez mais fora do centro de atenção da História, visto que são ações permanentemente e inconscientemente repetidas que governam as ações humanas e precisam ser estudadas e descritas.

A exclusão de qualquer relação de centralidade do homem, de qualquer hierarquia disciplinar ou de um continuum nos estudos da História é promovida pela terceira fase dos Annales no final da década de 60 e início da de 70. A também chamada Nova História Cultural foi a responsável por implodir a centralidade da História (com H maiúsculo), buscando torná-la o local principal de dispersão de qualquer discurso científico que buscasse a centralidade em substituição a ela. Autores como Pierre Nora, Jacques Le Goff e Paul Veyne passam a difundir que a história é regida pela preposição "de", ou seja, que a história só possui regras específicas a partir da série em que está colocada, dos conceitos imanentes do campo em que está interpretando. Assim, não existiria uma História orientadora de todo o campo do saber, mais uma história do solo, uma história das artes, história da sexualidade, história da religião, história política, e todas elas não teriam relação de hierarquia umas com as outras, visto que as regras de verdade e importância só diriam respeito a cada uma dessas áreas em específico. Essa posição gera, automaticamente, descontinuidade, já que os fatos não são vistos em um todo, em uma coerência que agrupa todos os acontecimentos em torno de uma unidade, seja ela o homem, um sistema econômico ou dado governo. Os fatos acontecem ao mesmo tempo e se colocam ao lado uns dos outros, pertencendo ao pesquisador a tarefa de tecer as relações pertinentes ao seu objeto de pesquisa.

A divisão da História em várias histórias permitiu o surgimento de inúmeros objetos possíveis de serem estudados pela área, alargando cada vez mais o seu leque de atribuições e as possibilidades de entrada nos documentos e no arquivo. Uma atenção

A exclusão de
qualquer relação
de centralidade
do homem, de
qualquer hierarquia
disciplinar ou de
um continuum nos
estudos da História
é promovida pela
terceira fase dos
Annales

A exclusão de qualquer relação de centralidade do homem, de qualquer hierarquia disciplinar ou de um continuum nos estudos da História terceira fase dos Annales 
maior é dada a regiões que não eram iluminadas pela história tradicional, tais como a história dos homossexuais, das mulheres, a história dos costumes, do comércio, do consumo, das formas de comunicação, do desejo, da vida privada. Ainda, permitiu uma variabilidade de formas de estudar a história, utilizando elementos estruturais da literatura e valorizando ainda mais o caráter autoral dos textos. Trata-se, definitivamente, de uma fuga da História que tentava se alicerçar pela cientificidade.

Pode-se dizer que, posteriormente à década de 80, muitos estudos buscaram recuperar a centralidade da História ou, ao menos, retirá-la desse centro de dispersão. Uma das obras que trabalha praticamente ao largo desse processo de congelamento ou de rompimento da História foi a de Paul Ricouer, especialmente seus três tomos em torno do Tempo e da Narrativa. O interessante nesse caso é que Ricouer vai estudar a História pelo lado de fora, a partir da Filosofia, procurando entender qual é a posição da narrativa histórica em relação às narrativas como um todo. Já François Dosse (2001 e 2007) procura recuperar todo o percurso da historiografia francesa e do Estruturalismo como forma de pensamento hegemônico do século daquele país.

Já no Brasil, identificam-se algumas importantes tendências que, inclusive, norteiam grande parte das pesquisas em História do Jornalismo. A primeira delas é a chamada História dos grandes eventos e das personalidades. Essa História busca unificar todos os fatos ocorridos na história do país a partir de sucessões presidenciais, sistemas de governo, a governabilidade e tudo que é inerente a ela (como revoltas, crises políticas, econômicas etc), guerras, feitos etc. Alia-se, portanto, a uma versão oficial da História que foi sistematizada no Brasil, inicialmente, por D. Pedro II com a criação de Institutos de Pesquisa, da Biblioteca Nacional e dos Museus. Essa tradição existe ainda hoje, com estudos de catalogação, histórias contadas a partir da cronologia governamental, centralidade nas grandes personalidades sob a forma de culto ao passado etc.

Uma segunda fase da Historiografia nacional é demarcada pela entrada das demais Ciências Humanas, em especial a Sociologia, a Economia e a Etnologia. Gilberto Freyre, por exemplo, introduz um modo diferenciado de pesquisa histórica ao buscar as raízes comportamentais da estrutura social do Brasil. Foi assim na sua trilogia mais famosa, Casa Grande e Senzala, Sobrados e Mucambos e Ordem e Progresso, onde o autor conta a história do Brasil colonial, imperial e republicano sem qualquer alusão à sucessão governamental. Freyre (2004), inclusive, introduz uma nova metodologia para a época, a História baseada em entrevistas realizadas com pessoas de diferentes situações sociais, dando voz e vida ao período de transição do Império para a República.
Uma segunda fase da Historiografia nacional é demarcada pela entrada das demais Ciências Humanas, em especial a Sociologia, a Economia e a Etnologia 
Ainda que Freyre seja reconhecido nacionalmente e internacionalmente por sua obra, a História brasileira pós anos 40 vai criticá-lo muito. Principalmente porque a teoria histórica-dialética marxista assume posição central nas universidades brasileiras e regem os estudos em História. A centralidade dos estudos é dada aos processos econômicos e políticos, utilizando a demografia, a estatística e a cartografia como bases para suas justificações e comprovações. Autores como Caio Prado Jr e Florestan Fernandes são exemplos de uma posição crítica em relação à História chamada oficial, às políticas do passado e do presente do Brasil e à situação de classes (área em que mais criticam Freyre), trazendo em suas obras a imanência da transformação social necessária ao país.

$\mathrm{O}$ que pode ser chamada terceira fase reflete, principalmente, as mudanças na História da década de 70 e que atingem o Brasil com maior força apenas a partir dos anos 90. Trata-se de uma abertura da história nacional para diversas áreas de interesse, envolvendo destacadamente o passado cultural do país. O interesse ampliou-se na direção das formas de consumo, da vida privada, da etiqueta, dos costumes, dos comportamentos, dando ao documento jornal uma importância que excede a verdade econômica e política. O jornal passa a ser um termômetro da forma com que as pessoas de uma dada época pensam e se comportam diante da realidade cotidiana. E muitos historiadores passam a enxergar novas possibilidades de pesquisa na prática e nos produtos do jornalismo.

\section{A História do Jornalismo}

Diante do percurso de Jornalismo e História, pode-se verificar como essa união gera dificuldades teóricas e metodológicas para os pesquisadores. O Jornalismo, um campo que ainda precisa alicerçar-se teoricamente e discutir mais enfaticamente seu verdadeiro objeto. Uma área transpassada por teorias e metodologias oriundas de outras áreas como Sociologia, a Lingüística, a Cultura, os Estudos Literários, a Política, a Economia etc. Uma relação que só pode ser avaliada diante da hibridez e na pressuposição de uma "região de retorno", sem os limites claros se esse retorno é possível por parte dos pesquisadores e sem a delimitação dessa região. Por outro lado a História, a primeira Ciência Humana, que passou por inúmeras transformações diante da emergência de outras disciplinas. Uma área que busca cientificidade nas suas relações com a Sociologia, a Lingüística ou a Antropologia e ainda imprime a essas uma centralidade que seria sua. Mas que, por outros autores, passa a reconhecer sua posição de igualdade com a área que estuda, participando ativamente do processo de descentralização de qualquer disciplina como orientadora. Um
O jornal passa a ser um termômetro da forma com que as pessoas de uma dada época pensam e se comportam diante da realidade cotidiana 
embate entre a História (com H maiúsculo) e a "história de". A História do Jornalismo, portanto, começa da união de duas áreas que permanentemente se chocam, visto que ambas querem alicerçar métodos e modos de observação. Uma disputa que não envolve apenas conceitos, mas também formação dos pesquisadores, orientação de programas de pós-graduação, congressos, revistas científicas, grupos de pesquisa.

A pertinência, portanto, passa a ser verificar como os pesquisadores relacionam História e Jornalismo com vistas a responder a um interesse mais pertinente ao campo jornalístico. Trata-se de uma busca ainda incipiente, visto que a história vem usando largamente os produtos e os processos do jornalismo para responder às suas demandas de pesquisa. Para isso, adota-se uma dupla estratégia como pressupostos norteadores: a) considera-se que o jornalismo possui uma região de retorno que precisa ser melhor definida e que os estudos nessa área podem constituir teorias, metodologias, ferramentas, hipóteses e objetivos pertinentes, capazes de delinear um objeto próprio de estudo; b) não será considerada a História em uma versão total e que abrange todas as esferas de pensamento das Ciências Humanas, mas como uma possibilidade de fornecer ao jornalismo subsídios para a compreensão dele como área, permitindo um recorte que o contemple em primazia. Ressalva-se que esses pressupostos não são conclusões, mas possibilidades de recortar o modo de observação e, ao mesmo tempo, uma busca por uma melhor compreensão do Jornalismo.

A união decorrente da História do Jornalismo nas pesquisas acadêmicas nem sempre revela uma posição fixa do Jornalismo e da História como está entendido aqui teoricamente. É possível verificar que o Jornalismo pode possuir cinco possíveis posições nos trabalhos sobre o tema (posições que em alguns casos se imbricam). a) Ele é visto como um documento de comprovação, atestando fatos que aconteceram em determinada época, registrando o comportamento da população, dos hábitos de divertimentos ou da deficiência de um serviço público, servindo assim como dado de resposta para as perguntas do pesquisador ao passado que não se interessa diretamente pelo jornalismo. b) Em muitos casos o estudo em história do jornalismo é justificado como a possibilidade de restaurar a memória do campo profissional, intelectual e empresarial, sendo constituído sob a forma de biografias (de jornalistas, donos de jornais, pesquisadores etc), história de empresas jornalísticas, de jornais alternativos, de sindicatos, partidos, governos etc, catalogações em geral, justificação de um legado a partir da recuperação de obras pioneiras sobre o assunto, demonstração de evoluções técnicas ou de conteúdo etc. c) Por vezes, o processo da notícia ou o produto é tratado como objeto
A História do Jornalismo, portanto, começa da união de duas áreas que permanentemente se chocam, visto que ambas querem alicerçar métodos e modos de observação 
central de análise em história do jornalismo, já que o pesquisador está interessado no modo de cobertura que o jornal realiza em uma dada época, nas estratégias que dispõe para narrar o fato, do modo com que os sujeitos aparecem no texto, na organização empresarial das companhias como interferentes em novos processos, nas possíveis formas de controle da notícia, no modo de trabalho dos repórteres, nas diferentes formas de resposta do público etc. Nesse caso, o jornalismo é estudado diante de um contexto dado, sem que esse contexto seja visto como mais importante do que ele. d) O Jornalismo também pode ser estudado como ator que interfere diretamente na realidade verificada, buscando reconhecer como o papel dessa atividade interfere e modifica o contexto social de um determinado período auxiliando na constituição de imaginários sociais e participando ativamente no processo de formação do público, da opinião pública e da postura de outros campos sociais. e) Por fim, o jornalismo pode ser colocado como pressuposto teórico norteador, indicando uma postura teórica que privilegia a formação desse campo de saber e busca utilizar e cunhar conceitos pertinentes à área a partir do estudo do fenômeno jornalístico ao longo da história. Nesse último caso, busca-se entender como a prática profissional, social, cultural e teórica ao longo da história referenda um exercício anacrônico e epistemológico para a constituição de conceitos capazes de contribuir para o entendimento do campo jornalístico.

Diante de um interesse teórico-metodológico próprio, as pesquisas que se consideram o jornalismo conforme categorias "c", "d" e "e", com suas possíveis hibridações, são mais estratégicas para a consolidação do campo teórico jornalístico. Isso porque elas não possuem o caráter exclusivo de memória e registro e não colocam o Jornalismo numa posição terceira, de simples comprovação de um interesse outro que não é pertinente com a área. Nesse aspecto, considera-se que é preciso avançar diante de posturas já referendadas ao Jornalismo como o do seu reconhecimento como documento histórico e também diante dos estudos descritivos que resgatam a memória. Como indica um estudo preliminar dos resumos das teses e dissertações nos cursos de Comunicação no Brasil de 1992 a 2002, as pesquisas que compreendem o jornalismo nas categorias "c", "d" e "e" ainda são minoria.

Já a História, por sua vez, pode ocupar quatro posições definidas a priori quando trabalhada com o Jornalismo. a) A História pode ocupar a posição de retorno ou origem, sendo que, nesse caso, o pesquisador faz um movimento ao passado para buscar os fundamentos de um dado fenômeno, por vezes, delimitando uma origem para a sua ação na sociedade. b) Em outro caso, a História pode manifestar e se justificar a partir de uma análise cronológica das transformações que passa uma prática, podendo 
receber para isso uma caracterização dialética, evolucionista ou episódica. c) Em outro aspecto, ela pode figurar como campo de justificação ou explicação de um fenômeno do presente. d) E, ela pode ser o pressuposto teórico norteador, capaz de fornecer os conceitos e ancorar a pesquisa a partir de teorias que sejam próprias do seu arcabouço, tecidas ao longo de sua história enquanto disciplina. Nota-se que essas quatro posições da História podem ser resumidos em duas, visto que as três primeiras tratam especificamente da relação de um fenômeno com o seu passado (relação diacrônica) e a última com a preocupação de perceber as regras com que o exercício histórico é constituído (relação sincrônica).

É visto que essas posições de Jornalismo e História na pesquisa não são estanques, cabendo ao pesquisador a dinamicidade de suas combinações e os resultados pertinentes delas. Contudo, nem sempre as pesquisas trazem apenas referências da História ou do Jornalismo. O que acontece, majoritariamente, é uma combinação de lentes, utilizando o conceito de Zelizer (2004) para atestar que os pesquisadores utilizam recursos de outras áreas como a Sociologia, a Economia, a Política, os Estudos da Linguagem, a Cultura etc. Nesses casos, não se trata apenas de História do Jornalismo, mas de História Social do Jornalismo, História Cultural do Jornalismo, História Política do Jornalismo, História Econômica do Jornalismo etc. Essa necessidade de "complementação" pode ser explicada, como uma hipótese, pela dupla abertura imposta pela união de História e Jornalismo. A primeira porque a História (seja ela considerada como universal ou como seriada) possui a característica de agregar-se ao campo que está auxiliando, exigindo dele parâmetros conceituais de justificação, instrumentos de aferição e a constituição de um objeto claro e referendado. Por outro lado, parece que o Jornalismo ainda não conseguiu uma autonomia política e conceitual capaz de dar plenamente essa sustentação que a História exige ao agregar-se com outra área. Isso abre espaço para uma terceira disciplina, mais fundamentada nas Ciências Humanas e com um maior poder de justificação alicerçado pelo volume de suas pesquisas e pela formação de seus pesquisadores.

A relação teórica tríplice entre história, jornalismo e outra lente pode ser representada de duas formas: por um triângulo, ou seja, em uma retro-alimentação, sem hierarquia estabelecida ou posição assumida, realizando, cada parte, contribuições teóricas, metodológicas, no processo de delimitação de objetivos e na definição do objeto; ou esses três vértices estariam em uma linha reta identificada com as regiões do recorte teórico, métodos de aproximação e análise e do objeto específico. Em alguns desses últimos casos, inclusive, o Jornalismo pode posicionar-se fora da reta, servindo apenas como uma região de comprovação, ou seja,

\section{Parece que o Jornalismo ainda não conseguiu uma autonomia política e conceitual capaz de dar plenamente essa sustentação que a História exige ao agregar- se com outra área}


apenas como documento que demonstra a existência de determinado fenômeno. Na maior parte dos casos, pelo que já foi visto nos 202 resumos destacados como História do Jornalismo entre as 3616 teses e dissertações defendidas nos programas de Mestrado e Doutorado em Comunicação no país de 1992 a 2002, o Jornalismo está localizado no objeto de análise. O recorte teórico e os métodos de aproximação ao objeto ficam sob disputa, sendo constantes as justificativas vindas das áreas auxiliares para o aumento da aprovação diante da comunidade científica.

Cada uma dessas combinações apresenta resultados de pesquisa diferentes, e a cada área que contribui para a História do Jornalismo, novas possibilidades teóricas e conceituais são abertas e uma nova dinamicidade envolve o campo. Se a necessidade de outros conceitos demonstra uma fraqueza epistemológica do Jornalismo, uma pesquisa que consiga congregar as estratégias que cada pesquisador utiliza para se justificar, por outro lado, pode contribuir para fortalecer o campo, identificando como o Jornalismo é trabalhado e como ele pode ser potencializado a produzir novos conhecimentos a partir da particularidade de sua prática.

Verifica-se que, ao tratar as fronteiras entre o pesquisador jornalista e o historiador, acaba-se afirmando também que tipo de conhecimento a pesquisa em Jornalismo pode oferecer. Enquanto os historiadores compartilham uma predisposição em tratar qualquer assunto, de qualquer área sob o ponto de vista do recuo no tempo e do recorte e com muitos interesses voltados para responder a questões pertinentes à História como um todo, o pesquisador em Jornalismo deve fixar sua área no fenômeno de mediação pertinente à atividade do jornalismo na sociedade.

$\mathrm{O}$ pesquisador em Jornalismo precisa colocar seu interesse sob uma predisposição de consolidação da compreensão conceitual e teórica do Jornalismo. Não bastaria ao pesquisador interessado em fundamentar o campo tratar o Jornalismo apenas como objeto de justificação de um tema terceiro ou como levantamento de uma memória incapaz de contribuir mais efetivamente com o movimento de recuperação teórica do jornalismo. O objetivo é, portanto, demonstrar a pertinência que os estudos em História do Jornalismo possuem na compreensão teórica e prática do Jornalismo, demonstrando que essa modalidade de investigação é um dos pilares fundamentais para a pesquisa na área.

A pesquisa em História do Jornalismo pode responder ainda a muitos impasses decorrentes da busca pela legitimação do Jornalismo como campo de saber. A demarcação mais ampla do objeto do Jornalismo quando tratado pela História do Jornalismo visa responder àqueles que definem o Jornalismo apenas como uma profissão e àqueles que o apontam como conhecimento, mas ainda teimando em defini-lo apenas pelo viés da profissão. O Jor-
O pesquisador em Jornalismo precisa colocar seu interesse sob uma predisposição de consolidação da compreensão conceitual e teórica do Jornalismo 
nalismo não irrompe a História apenas como uma profissão, mas como uma atividade intelectual que envolve relações de poder e de saber, que cria e é criado por um público e que dinamiza as concepções de cidadania, de povo, de direitos, de liberdade, de entretenimento, de curiosidade, do presente e protagoniza a própria consolidação da coisa pública. Questões que cabem ao Jornalismo investigar.

\section{Referências}

BACHELARD, Gaston. A Formação do Espírito Científico. Rio de Janeiro: Contraponto, 1996.

BARBOSA, Marialva. História Cultural da Imprensa. Brasil - 1900-2000. Rio de Janeiro: Mauad X, 2007.

BARBOSA, Marialva; RIBEIRO, Ana Paula G. O que a História pode Legar aos Estudos em Jornalismo? Contracampo: Revista do Mestrado em Comunicação, Imagem e Informação. Niterói: Universidade Federal Fluminense, v. 12 , p. 51-61, 1 sem de 2005.

BELAU, Angel F. La Ciencia Periodística de Otto Groth. Pamplona (Espanha): Instituto de Periodismo de la Universidad de Navarra, 1966.

BERGER, Christa; MAROCCO, Beatriz (org). A Era Glacial do Jornalismo: Teorias sociais da imprensa. Porto Alegre: Sulina, 2007.

BOURDIEU, Pierre. O Campo Científico. In ORTIZ, Renato (org). Pierre Bourdieu. São Paulo: Ática, 1983, p. 122-155.

Sobre a televisão. Rio de Janeiro: Jorge Zahar, 1997.

Campo de Poder, Campo Intelectual. Buenos Aires: Editorial Quadrata, 2003.

BRAGA, José Luiz. Constituição do Campo da Comunicação. In: FAUSTO NETO, Antônio; PRADO, José A.; PORTO, Sergio D. Campo da Comunicação. João Pessoa: Editora Universitária, 2001.

BURKE, Peter (org). A Escrita da História - Novas Perspectivas. São Paulo: Editora Unesp, 1992.

DOSSE, François. A História à Prova do Tempo. São Paulo: Editora UNESP, 2001.

História do Estruturalismo. Bauru (SP): EDUSC, 2007.

FOUCAULT, Michel. A História da Sexualidade - A vontade de saber. 6 ed. Rio de Janeiro, Graal, 1985.

As Palavras e as Coisas: uma arqueologia das ciências humanas. 8

ed. São Paulo: Martins Fontes, 2002.

Arqueologia do Saber. 7 ed. Rio de Janeiro: Forense Universitária,

2005.

A Ordem do Discurso. 12 ed. São Paulo: Loyola, 2005b.

Arqueologia das Ciências e História dos Sistemas de Pensamento.

Ditos e Escritos vol. 2. Organização e seleção de textos: Manoel Barros da Motta. 2 ed. Rio de Janeiro: Forense Universitária, 2005c.

FREYRE, Gilberto. Sobrados e Mucambos: decadência do patriarcado rural e desenvolvimento do urbano. Tomo 1 e 2.5 ed. Rio de Janeiro: Livraria 
José Olympio, 1977.

Ordem e Progresso. 6 ed. São Paulo: Global, 2004.

GENRO FILHO, Adelmo. O Segredo da Pirâmide: Por uma teoria marxista do jornalismo. Porto Alegre: Tchê, 1987.

GOMIS, Lorenzo. Teoría Del Periodismo: Como se forma el presente. Barcelona: Paidós, 1991.

HARDT, Hanno. Social Theories of the Press. New York: Rowman \& Littlefield, 2001.

HARTLEY, John. Popular Reality: Journalism, modernity, popular culture London/ New York: Hodder Arnold, 1996.

HUGHES, Helen M. News and the Human Interest Story. New Brunswick (USA) and London: Transaction Books, 1981. Original de 1940.

LE GOFF, Jacques. A Nova História. São Paulo: Martins Fontes, 1998.

LEVI-STRAUSS, Claude. Antropologia Estrutural Dois. Rio de Janeiro: Tempo Brasileiro, s/d.

O Pensamento Selvagem. São Paulo: Cia Editora Nacional, 1976.

LIPPMANN, Walter. Public Opinion. Mineola - NY: Dover Publications, 2004. Original de 1922.

MACHADO, Roberto. Ciência e Saber: A trajetória da arqueologia de Michel Foucault. 2 ed. Rio de Janeiro: Graal, 1981.

MEDITSCH, Eduardo. O Conhecimento o Jornalismo. Florianópolis: Editora da UFSC, 1992.

MORETZOHN, Sylvia. Pensando Contra os Fatos: jornalismo e cotidiano - do senso comum ao senso crítico. Rio de Janeiro: Revan, 2007.

PARK, Robert. The Crowd and the Public and Other Essays. Chicago/ London: The University of Chicago Press, 1972. Original de 1904.

PEUCER, Tobias. De relationibus novellis. Leipzig: Tese (Doutorado em Periodística) - Universidade de Leipzig, 1690. Tradução de Paulo da Rocha Dias. São Bernardo do Campo: PósCom-Umesp, 1999.

PONTE, Cristina. Para Entender as Notícias: Linhas de análise do discurso jornalístico. Florianópolis: Insular, 2005.

Lentes Cruzadas na Pesquisa em Jornalismo: a proposta de Barbie

Zelizer. Trabalho apresentado no XXVIII Congresso Brasileiro de Ciências da Comunicação. Rio de Janeiro: UERJ, 2005b.

PRADO JUNIOR, Caio. História Econômica do Brasil. São Paulo: Brasiliense, 1976.

RODRIGUES, Adriano Duarte. Estratégias da Comunicação. Lisboa: Presença, 1990.

ROGERS, Everett. A History of Comunication Study. New York: Free Press, 1997.

ROMANCINI, Richard; LAGO, Cláudia. História do Jornalismo no Brasil. Florianópolis: Insular, 2007.

História e Jornalismo: reflexões sobre campos de pesquisas. In

LAGO, Cláudia; BENETTI, Márcia (org). Metodologia de Pesquisa em Jornalismo. Petrópolis RJ: Vozes, 2007, p. 23-47.

SCHUDSON, Michael. Discovering the News: A social history of american 
newspapers. New York: Basic Books, 1978.

Enfoques históricos a los estúdios de la comunicación. In JENSEN, K. B; JANKOWSK, N. W. (eds). Metodologias Cualitativas de Investigación em Comunicación de Masas. London: Routledge, 1993

The Power of the News. Cambridge/ Massachusetts: Harvard University Press, 1995.

SAUSSURE, Ferdinand. Curso de Linguística Geral. São Paulo: Cultrix, 2001.

SLOAN, Wm David. Makers of the Media Mind: Journalism educators and their ideas. Mahwah/ New Jersey: Lawrence Erlbaum, 1990.

SODRÉ, Nelson Werneck. História da Imprensa no Brasil. Rio de Janeiro: Mauad, 1999.

SOUZA, Jorge Pedro. Teorias da Notícia e do Jornalismo. Chapecó: Argos, 2002.

STUMPF, Ida R; CAPPARELLI, Sérgio (orgs). Teses e Dissertações em Comunicação no Brasil: Resumos 1997-1999. Porto Alegre: PPGCom/ UFRGS, 2001.

TARDE, Gabriel. A Opinião e as Massas. São Paulo: Martins Fontes, 1992. Original de 1901.

TRAQUINA, Nelson. Teorias do Jornalismo: porque as notícias são como são - Vol. 1. Florianópolis: EDUFSC, 2004.

VEYNE, Paul. Como se Escreve a História. Lisboa: 70, 1983.

Foucault Revoluciona a História. Brasília: Editora da Universidade de Brasília, 1998.

WILKERSON, Marcus M. History and Journalism Research. In: NAFIZIGER, Ralph O; WILKERSON, Marcus M. An Introduction to Journalism Research. New York: Greenwood Press Publishers, 1968, p. 09-25.

ZELIZER. Barbie. Taking Journalism Seriously: News and the academy. London: Sage, 2004.

Recebido em 30 de agosto de 2008 Aprovado em 25 de outubro de 2008 